\title{
ESTADO Y ALIANZAS..., CUARENTA AÑOS DESPUÉS ELEMENTOS PARA PENSAR EL GIRO A LA DERECHA EN ARGENTINA
}

\section{Gabriel Vommaro}

\section{Resumen}

Este artículo vuelve sobre una gran pieza de economía política escrita por G. O'Donnell, Estado y alianzas en la Argentina, 1956-1976. El objetivo es, por un lado, revisitar la riqueza de un estilo de trabajo que combinaba preocupación por factores estructurales y procesos políticos y articulaba las miradas sociológica, politológica y económica, lo que se ha vuelto poco frecuente con la hiperespecialización de las ciencias sociales. Por otro lado, se trata de movilizar el esquema de análisis que el autor desarrolló en aquel ensayo para comprender el proceso político iniciado en Argentina en 2015 con el triunfo de una fuerza política de centro-derecha, que rompe con la debilidad electoral de ese espacio.

Palabras clave: economía política / sociología política / coaliciones políticas y sociales / Argentina.

\begin{abstract}
State and alliances..., forty years after. Elements to think the right turn in Argentina

This article returns on a great piece of political economy written by G. O'Donnell, State and alliances in Argentina, 1956-1976. The objective is, on the one hand, to revisit the richness of a work style that combined concern for structural factors and political processes and articulated sociological, political and economic views, which has become rare with the hyperspecialization of the social sciences. On the other hand, the objective is to mobilize the analysis scheme that the author developed in that essay to understand the political process initiated in Argentina in 2015 with the triumph of a center-right political force that breaks with the electoral weakness of that spectrum.

Keywords: political economy / political sociology / political and social coalitions / Argentina.

\footnotetext{
Gabriel Vommaro. Doctor en Sociología por la Escuela de Altos Estudios en Ciencias Sociales (Francia), profesor en la Universidad Nacional de San Martín, investigador del Consejo Nacional de Investigaciones Científicas y Técnicas, especializado en temas de sociología política.

E-mail: gvommaro@unsam.edu.ar
} 


\section{Introducción}

En diciembre de 1976 Guillermo O’Donnell presentó en un simposio en la Universidad de Cambridge un ensayo que intentaba reconstruir el ciclo político pendular vivido por Argentina desde la caída del primer peronismo en 1955 hasta el golpe de Estado de 1976. Este ensayo fue publicado por la revista Desarrollo Económico a comienzos de 1977 y, ese mismo año, por el Centro Brasileño de Análisis y Pensamiento (CEBRAP), institución en la que O'Donnell tuvo un rol fundamental. De modo que en Estado y alianzas en la Argentina, 1956-1976 (Estado y alianzas..., en adelante) se unen dos de los "hogares" intelectuales que forman parte central del derrotero académico del autor.

El trabajo sigue una perspectiva histórica para buscar en la evolución de las alianzas de clase y fracciones de clase producidas durante ese período - así como de la intervención del Estado a favor de una o de otra alianza - algunos rasgos explicativos generales del proceso de gobiernos civiles débiles interrumpidos por gobiernos militares con voluntad de refundación que signó a Argentina durante buena parte del siglo XX. En diálogo con El Estado burocrático-autoritario (O'Donnell, 1982), escrito entre 1974 y 1976 pero publicado recién en 1982, O’Donnell realizó un análisis de las "tendencias de largo plazo que enmarcan a dichas coyunturas y, a la vez, permiten ligarlas con el proceso histórico en el que han emergido y se han disuelto" (O’Donnell, 1977, p. 521).

En definitiva, es en la articulación de las estrategias de los actores y de los factores estructurales que condicionan sus decisiones - asociados tanto con la distribución desigual de recursos como con inercias históricas institucionalizadas - que el autor encontró las claves explicativas de la inestabilidad del ciclo, que comenzó con la caída del primer peronismo y culminó con la instauración de la última dictadura militar. En él se desplegó toda la complejidad de la "Argentina peronista", el fenómeno político crucial de la segunda mitad del siglo XX, que sin duda había alterado los modos en que se ordenaban y se percibían las relaciones entre los grupos sociales.

Precisamente, el ensayo de O’Donnell se ocupó de analizar la crisis de la hegemonía de la fracción más antigua de la burguesía argentina - el sector agrario pampeano - y las dificultades para instaurar una dominación duradera por parte de la llamada "alianza defensiva", constituida "básicamente por el sector popular y por fracciones débiles de la burguesía urbana" (1977, p. 537) y expresada de manera histórica en el peronismo. 
En este texto nos preguntaremos, primero, ¿qué nos muestra el ensayo sobre el modo de estudiar la política que empleaba O'Donnell?; segundo, ¿cómo pensar la Argentina reciente a partir de las coordenadas provistas por el autor? Al respecto, nos enfocaremos en las características de una relativa novedad en relación con el ciclo analizado en ese ensayo: el hecho de que la crisis de expresión política de la burguesía agraria podría haber encontrado una solución, al menos transitoria, con la conformación de un polo competitivo de centro-derecha, la coalición Cambiemos, que llegó a la presidencia de la nación en 2015. Las páginas que siguen reflexionan sobre estas cuestiones en un estilo ensayístico, sin movilizar elementos empíricos conclusivos, aunque den cuenta de algunos datos que sostienen nuestros argumentos.

\section{Un análisis político estructural, no determinista, anclado social y económicamente}

La perspectiva de análisis de la política basada en una combinación de sociología y economía políticas fue uno de los estilos de trabajo fundamentales de la investigación en ciencias sociales en la Argentina de la segunda mitad del siglo XX (Vommaro y Gené, 2017b). En diálogo con la historia, con la teoría social y con la teoría y la ciencia política, esta perspectiva multidisciplinar avant la lettre se interrogó sobre todo por la constitución del peronismo y los procesos sociopolíticos que le habían dado nacimiento, así como los que este traía como novedad.

Las investigaciones fundadoras de Gino Germani (1962) combinaban prácticas creativas y muchas veces inéditas de construcción de información empírica con la movilización de un conjunto de herramientas conceptuales, tomadas de las teorías de la modernización y de la movilización social, que le permitieron proponer una explicación sobre el modo en que el movimiento naciente, por un lado, había conseguido la incorporación de vastos contingentes sociales a la vida política y, por otro lado, había sido el vehículo por el que, por primera vez en la historia del país, se conformó un electorado legible en términos de clase, y en especial un electorado consistente y mayoritariamente constituido en torno a la clase obrera (Germani, 1955), como núcleo de lo que O'Donnell llamaría luego "el sector popular".

El uso creativo de diferentes fuentes metodológicas también estaría presente en los trabajos de O'Donnell - quien había tenido contacto con Germani-, y se vio reflejado, a lo largo de su obra, en la combinación de una perspectiva histórica con la estadística económica, de la teoría institucional de la política con la etnografía "silvestre" movilizada, por ejemplo, en el célebre texto ¿Y a mí, que me importa? (O’Donnell, 1984), al que nos referiremos luego. 
Este estilo de trabajo hizo posible conectar procesos sociales y económicos, que podríamos llamar estructurales - la transformación del capitalismo argentino-, con procesos políticos vinculados a la constitución de cierto tipo de alianzas entre actores - militares, sindicales, partidarios - que, en esas condiciones socioeconómicas, definían estrategias en defensa de modelos de país con certeza opuestos, en los que ambos componentes - los procesos sociales y económicos y los procesos políticos - se anudaban de modo diferente. En esta combinación se advierte con claridad la inspiración marxista, por un lado, y weberiana, por el otro, de los trabajos de O'Donnell, en especial en los años setenta y ochenta, en los que se ocupó de estas dos cuestiones: las alianzas entre actores sociales y políticos y el rol del Estado en el establecimiento de un modelo económico que asignaba "ganadores" y "perdedores". A estos dos asuntos nos referiremos enseguida.

\section{El Estado y las alianzas en la Argentina pendular: algunos comentarios}

Estado y alianzas... explica la dinámica política pendular que dominó el país entre 1956 y 1976 en función de: primero, las condiciones estructurales de las relaciones políticas, ya que las clases y fracciones de clase estudiadas se vinculan entre sí en virtud del conflicto distributivo, y en especial en torno a la apropiación de bienes exportables, que son también bienes de consumo masivo; segundo, la historicidad de la conformación de esos grupos: en lugar de pensar en actores determinados de forma pura por las relaciones de producción, O’Donnell se ocupó de sus condiciones históricas de construcción, y de los recursos económicos, sociales y políticos con los que se equiparon en ese recorrido. Las clases sociales, así, viven en la dinámica histórica a través de los grupos movilizados que les dan cohesión, programa y, en cierto sentido, una identidad. No hay, entonces, una mirada objetivista de las clases que haga proceder mecánicamente "del papel", por hablar como Pierre Bourdieu, su intervención en la historia ${ }^{1}$.

El autor identificó dos grandes colectivos en conflicto en la historia Argentina de la segunda mitad del siglo XX: de un lado, una burguesía pampeana conectada con el mundo pero, desde los años veinte, con serias dificultades para construir una expresión política propia competitiva y duradera, que logró atraer a otros grupos burgueses, también trasnacionalizados, que fueron aliados circunstanciales de un proyecto "disciplinador" en los ciclos políticos regresivos; del otro, unas clases populares relativamente fuertes en cuanto a su capacidad de presión, identificadas en su mayoría con el movimiento po-

1 Para Bourdieu, en efecto, las clases existen "en el papel", como probabilidad teórica, lo que no debe confundirse con su existencia "real", dada desde el momento en que se conforma un grupo con capacidad de movilización, portavoces, organizaciones e ideologías que mantienen unidos a sus miembros. Cf. Bourdieu (1984). 
lítico peronista, pero con limitaciones importantes para superar la dinámica corporativa y construir un proyecto económico duradero.

Por eso es que solo tuvieron el apoyo de las fracciones más débiles de la burguesía, aquellas que dependían más del mercado interno. En este contexto, emerge la importancia del Estado, que es, a la vez, sujeto de una historia pendular y eje central del conflicto político. En tanto poseía baja autonomía respecto de los grupos en lucha, en cada coyuntura era "arrastrado" por los actores que lograban controlar su dirección. Veamos con más detalle algunos de estos rasgos del Estado y las clases.

\section{Las burguesías argentinas}

O’Donnell dividió a la burguesía en "burguesía doméstica" y "burguesía trasnacional", en virtud del origen del capital, y en "gran burguesía urbana" (industrial) y "burguesía pampeana", en virtud del tipo de actividad (y aquí ya no importa el origen del capital). Luego se ocupó también de su "tamaño": gran, mediana y pequeña burguesía. En todos los casos, lejos de aparecer como un actor monolítico, las diferentes fracciones de esa clase podían actuar diferente según primase una u otra dimensión que caracteriza su composición (el elemento nacional, el tamaño, los intereses sectoriales, etcétera). En ciertas coyunturas, entonces, la gran burguesía urbana, de origen extranjero predominante, se plegaba a la burguesía pampeana, y en otras se asociaba a la mediana y pequeña para aprovechar las protecciones aduaneras. En líneas generales, O’Donnell habló del "clivaje interburgués" (1977, p. 533) que impedía a esa clase construir un bloque consistente a lo largo del tiempo, lo que constituía una particularidad del caso argentino que estaba en la base de la debilidad de la conformación de una hegemonía duradera.

Esta dificultad se asociaba también con la debilidad - o inexistencia - de una expresión político-partidaria de estos sectores. Si los clivajes interburgueses obstaculizaban la agregación de intereses intersectoriales, la falta de organizaciones partidarias representativas agudizaba la imposibilidad de proponer un proyecto en condiciones de incorporar mayorías sociales. En ese contexto, los sectores burgueses más dinámicos se apoyaron en el actor militar para imponer un orden que interrumpía el ciclo de predominio popular, revertía sus conquistas y producía un ajuste del gasto público vinculado con estas. Ese impulso llevaba entonces a una situación de debilidad política y de movilización social que desembocaba en un nuevo ciclo de la alianza defensiva.

\section{"El sector popular" y sus limitaciones}

O’Donnell identificó dos rasgos centrales de este sector, y en especial de su relación con las distintas burguesías. Por un lado, la clase obrera industrial tenía un peso preponderante en Argentina. Su agrupamiento en sindicatos 
fuertes la dotaba "de recursos económicos y organizativos significativamente mayores que los del resto de América Latina" (1977, p. 531). Por otro lado, como dijimos, se encontraba en un conflicto estructural con la burguesía pampeana, ya que los principales productos de exportación de la economía argentina eran, al mismo tiempo, "alimentos que constituyen el principal bien-salario del sector popular" (1977, p. 531). En estas condiciones, las ganancias de una clase estaban en directa oposición, quizás de manera más brutal que en otros casos, a los ingresos de la otra.

En otro trabajo, de orden más etnográfico que de análisis estructural, que O’Donnell titularía ¿Y a mí, que me importa? (1984), el autor asoció este poder de movilización del sector popular a una suerte de plebeyismo a medio camino, que desconocía - "mandaba a la mierda" - las jerarquías sociales, es decir, la primacía del actor burgués y en especial de la burguesía pampeana, sin llegar a cancelarlas. $\mathrm{O}$, en otros términos, pretendía instituir una sociabilidad igualitaria que no dejaba de reconocer su base social jerárquica. Este desajuste estaba en buena medida en la raíz de los límites de la acción sindical en Argentina, pero también de la inestabilidad de los proyectos burgueses, que no lograban el reconocimiento popular y que siempre se sentían acorralados por esa irreverencia que acechaba su posición simbólica sin desafiar su situación estructural.

Dicho rasgo de la así llamada "cultura política" argentina se jugó, para O'Donnell, tanto en el orden micro como en el macro: en el plano de las prácticas cotidianas generaba encuentros sociales violentos e igualitarios; en el plano de la vida política, un conflicto de larga data y de base estructural, lo que lo volvía sólido y duradero. En otras palabras, ¿Y a mí, que me importa? recoge, en términos cotidianos, aquello que, siete años antes, O’Donnell había identificado en Estado y alianzas... en términos estructurales: una "apariencia de igualdad" entre los actores corporativos - de un "corporativismo anárquico"- que escondía diferencias de recursos flagrantes. La distancia entre la igualdad aparente y la desigualdad consistente se puso de manifiesto en los ciclos descendentes del sector popular, que coincidieron, durante el siglo XX, como dijimos, con golpes militares en los que la represión desarticulaba toda forma de protesta mediante métodos represivos duros, al tiempo que se producían rápidas transferencias de recursos del sector asalariado a la gran burguesía.

Las consecuencias de estos ciclos descendentes sobre los ingresos del sector popular nunca terminaban de revertirse en las fases ascendentes. Y es por eso que, contra la idea del "empate hegemónico" (Portantiero, 1977), para O'Donnell la historia pendular de la Argentina de los años peronistas era la de una lenta pero continua derrota de las clases populares, al menos desde 1955 (O’Donnell, 1984, p. 24). La última dictadura militar, a comienzos de la cual O'Donnell escribió Estado y alianzas..., vino a cerrar ese proceso acelerando la derrota y volviéndola inexorable. En ese contexto, la cultu- 
ra plebeyista argentina fue el blanco principal del "disciplinamiento social" que, como sostuvo Adolfo Canitrot (1980), se propuso llevar adelante esa dictadura. En el diagnóstico de la derecha argentina que acompañó al gobierno militar, se trataba de terminar con ese "país ingobernable", como lo señaló O’Donnell (1984, p. 16).

Ante semejantes perspectivas, ¿cómo se podía salir de la encerrona a la que habían llevado el conflicto de clases en Argentina? El O'Donnell de fines de los años setenta y principios de los ochenta buscaría una respuesta en la instauración de un régimen democrático estable, con la institucionalización del conflicto político y con la mediación de actores partidarios que tamizaran los intereses sociales en pugna. A la salida de la última dictadura militar, identificó los cimientos de una sociedad "autoritaria y violenta" (1984, p. 5) en la ausencia de "espacios posibles de acuerdo, cooperación y establecimiento de reglas más o menos estables y generalmente compartidas" (1984, p. 23). En ese contexto, propondría mecanismos institucionales de superación de la violencia política que había caracterizado a esa sociedad en tensión y que se hallaba enraizada en esas relaciones igualitarias al tiempo que jerárquicas entre actores burgueses dominantes y sector popular. De allí que, en sus trabajos posteriores, pensó las condiciones para, por un lado, fortalecer las mediaciones políticas que hicieran gobernables los intereses sociales y económicos - los partidos y sus portavoces - y, por otro lado, establecer instancias de acuerdo - pactos, dirían los transitólogos argentinos - que posibilitasen definir algunos criterios de distribución del excedente y, por tanto, algunas coordenadas de funcionamiento de un modelo económico y social duradero.

\section{Sobre el Estado}

O’Donnell sostuvo que el Estado argentino nació con la marca de la burguesía agraria pampeana, poderosa y bien conectada con el mercado mundial, que era, al menos hasta las primeras décadas del siglo XX, un elemento central en su reproducción. Por un lado, entonces, ese Estado fue "creatura de la burguesía pampeana y de sus prolongaciones financieras y comerciales en el sector urbano, a través de un proceso que también implicaba la constitución de esa burguesía, y del sistema que dominaba, en apéndice directo y altamente internacionalizado del mercado mundial" (1977, p. 529). Creatura e instrumento de esa burguesía, el Estado tendría dificultades para construir competencias autónomas una vez que debió lidiar con una sociedad más compleja, con actores sociales movilizados y pujas distributivas pronunciadas.

El problema es que ese Estado nunca funcionó como "instancia de reformulación de intereses más generales", ni como espacio de "generalización", es decir, de construcción de relaciones estables entre las partes en disputa en la sociedad, sino que fue más bien un "campo de batalla" (O’Donnell, 1984, pp. 
21-22). El tercer elemento que pensó O'Donnell a partir de los años ochenta fue el fortalecimiento del poder del Estado, en especial en su dimensión infraestructural, para utilizar los términos de Michael Mann (1984), y a la vez con capacidad de garantizar un tipo de relación más o menos homogénea con sus ciudadanos, tanto en lo geográfico como en el ámbito de las diferentes clases sociales.

\section{Leer a O'Donnell desde el presente}

Los efectos de la última dictadura militar serían duraderos, tanto en términos económicos como políticos. Los juicios a los responsables del terrorismo de Estado, llevados a cabo por iniciativa del gobierno radical iniciado en 1983, y la acción de los organismos de derechos humanos contribuyeron a construir un piso social compartido en torno a la cuestión de los derechos civiles y políticos que transformó, de manera definitiva, la cultura política argentina. Y lo hizo en un sentido similar al esperado por O'Donnell: implicó el rechazo unánime de la violencia como mecanismo de resolución de conflictos y un creciente apego a la democracia institucional. En este sentido, el país emergió de la última dictadura con un acuerdo cada vez más amplio respecto a la aceptación de lo que O'Donnell llamó "ciertos valores y prácticas más democráticas y convivenciales" (1984, p. 17). Menos exitoso fue, en cambio, el intento de los partidos políticos de convertirse en mediadores privilegiados de las demandas de los diferentes sectores sociales. Aunque se establecieron como actores más estables, con el horizonte regular que marca la vida electoral, el debilitamiento de los lazos representativos les impidió consolidarse como representantes de electorados bien delimitados. Eso impactó con fuerza, en los años noventa y hasta los dos mil, en el sector no peronista del electorado (Torre, 2003); a partir de 2015, luego de un largo ciclo de predominio de un peronismo nacionalpopular que en parte se propuso revertir algunas de las consecuencias del ciclo regresivo iniciado en 1976 y que culminó, en términos económico-sociales, en 2002, parece estar sucediendo algo similar con el sector peronista.

En cuanto a los grupos de interés y los actores sociales organizados, estos siguieron operando sobre el Estado en condiciones muy desiguales, pero siempre con base en acuerdos particularistas que incluían la búsqueda de ventajas de corto plazo, incluso en detrimento de ganancias sectoriales. Ana Castellani (2007) estudió la consolidación, en el ciclo democrático, de lo que llama "ámbitos privilegiados de acumulación", es decir, entramados de relaciones entre actores públicos y privados que permiten a los segundos obtener rentas extraordinarias con base en la consecución de subsidios o de protecciones especiales por parte del Estado. María Victoria Murillo (1997) y Sebastián Etchemendy (2001), en tanto, se ocuparon de las estrategias de negociación del Estado con los actores sindicales en los años noventa, que permitieron a estos últimos controlar recursos organizativos a cambio de ceder en protecciones sociales para sus afiliados. 
Desde el Estado, los gobiernos construyeron mecanismos informales de negociación que fortalecieron a los actores más poderosos. Para aquellos que poseían menos capacidad de negociación en esas mesas informales, se impuso el recurso a la movilización y la acción directa, en especial en el sector popular (Merklen, 2005). Entretanto, el Estado solo mejoró sus capacidades y su poder - infraestructural y despótico - en algunas de sus agencias, que fueron la excepción más que la regla tanto en la continuidad de políticas a lo largo de todo el ciclo democrático como en la estabilización de sus cuadros y procedimientos ${ }^{2}$.

La estabilización de la democracia electoral consolidó élites políticas heterogéneas que tuvieron problemas para construir modelos económicos duraderos. La debilidad de los acuerdos generales se vio plasmada, con particular intensidad, en la suerte de las políticas económicas que propusieron las diferentes alianzas sociales que convocaron, desde arriba, las circunstanciales élites en el gobierno. Con el proceso de desindustrialización y de apertura económica, la dictadura militar iniciada en 1976 debilitó - sin suprimirlas las bases de poder de los sindicatos, así como de la pequeña y mediana burguesía urbana (Sidicaro, 2002). La alianza "defensiva" que había ocupado el centro de la escena en los períodos democráticos del ciclo pendular analizado por O'Donnell perdió, de ese modo, buena parte de sus recursos organizativos y de los resortes que empujaban un proceso de crecimiento basado en el mercado interno.

Tras los primeros intentos de reanudar un proyecto mercadointernista, el radicalismo cedió al realismo económico e inició un ajuste gradual que, tras la crisis hiperinflacionaria de 1989, fue acelerado por las reformas neoliberales de los años noventa, que parecían llevar a Argentina, definitivamente, a un modelo de economía abierta y de flexibilización de las protecciones sociales. En cierta medida, como sostuvimos antes, la alianza defensiva pudo ser reanudada de manera parcial en los años dos mil en condiciones muy particulares, con la apropiación por parte del Estado de parte del excedente extraordinario producido por el auge de las commodities (productos básicos).

El conflicto entre el gobierno peronista nacional-popular de esos años y las entidades agropecuarias en 2008 expresó los límites de la legitimidad de esta iniciativa redistributiva (Aronskind y Vommaro, 2010) ${ }^{3}$. Con el declive del precio internacional de las commodities volvieron los viejos problemas

2 Sobre este punto, cf. Acuña (2013).

3 Se trata del conflicto iniciado por la oposición de las principales entidades que agrupan a los productores rurales a la modificación del régimen de derechos a las exportaciones de granos (conocidas por "retenciones"), decidida por el gobierno de Cristina Fernández de Kirchner en marzo de 2008, en previsión de un alza del precio internacional de esas commodities. El conflicto produjo una ruptura profunda entre el sector agrario y el peronismo nacional-popular, que se expresó más tarde a nivel electoral (Mangonnet, Murillo y Rubio, 2018). 
de la economía argentina, que expresaban la puja entre proyectos económicos opuestos de características similares a los que había descrito O'Donnell en su ensayo. La crisis de legitimidad de ese gobierno y el fin del ciclo político inaugurado en 2003 como respuesta al agotamiento del programa aperturista de los años noventa dio lugar... al triunfo de un nuevo programa aperturista. Esta vez, sin embargo, con una novedad: por primera vez en casi un siglo, una fuerza partidaria de centro-derecha ganaba elecciones libres, sin proscripción, y accedía al poder por la vía institucional. En efecto, el partido Propuesta Republicana (PRO), como socio principal de la coalición Cambiemos, llegó al poder por la vía electoral en 2015. Fundado en 2001, primero como think tank (centro de pensamiento), por el heredero de uno de los principales grupos económicos argentinos, se trata de una fuerza pragmática, con creciente capacidad competitiva y autónoma de los partidos mayoritarios que habían sido vía de acceso de los grupos de derecha al poder en el actual ciclo democrático (Vommaro, et al., 2015). Su promesa de producir un "cambio cultural" en Argentina luego del triunfo sobre el candidato presidencial peronista puede ser interpretada, en cierta medida, como parte de ese péndulo histórico que describimos, pero, al mismo tiempo, introdujo la novedad de lograr vencer a la "alianza defensiva", por así decirlo, en su propio terreno: el de la legitimidad electoral.

¿Puede debilitarse el plebeyismo que caracterizó a la cultura política argentina? Ahora que una parte de las élites sociales y económicas se integró a una fuerza política sin raíces plebeyas y llegó al gobierno, ¿es esto un signo de la crisis de las identidades nacional-populares? ¿Llegará el tiempo de una dominación burguesa durable, que privilegie la integración del país en los mercados mundiales antes que el desarrollo de su mercado interno, y que esta vez lo haga con apoyos masivos? ¿Podrá, finalmente, la derecha social "producir una idea" (O’Donnell, 1984, p. 16) que pueda volverse rectora de un orden político estable con base en jerarquías económicas legítimas?

Nuestra respuesta tendría que emerger, si seguimos a O'Donnell, de un recorrido por la historia reciente de Argentina y del estudio de las nuevas condiciones estructurales en las que se define el conflicto político. Digamos, por una parte, que esta centro-derecha de ideología pragmática y flexible (Vommaro, et al., 2015), para obtener su triunfo electoral, tuvo que aceptar buena parte de los bienes colectivos instituidos durante los años del ciclo nacional-popular anterior, lo que incluye el mantenimiento de políticas sociales masivas para los pobres informales urbanos y la continuidad de las negociaciones salariales para los trabajadores formales. Con matices no sin importancia, que obviamos en estas páginas, estas instituciones del bienestar popular perduran hasta el momento en que escribimos este texto en un estado similar al que legó el período anterior (Vommaro y Gené, 2017a). 
Sin embargo, los diagnósticos del nuevo gobierno en materia de economía política hacen augurar que ese posibilismo está en tensión con las miradas de largo plazo del núcleo que orienta la coalición gobernante. Por un lado, algunos análisis de sus voceros económicos parecen puntualizar, en consonancia con la vieja derecha argentina a la que se refería O'Donnell, que la principal causa del péndulo al que está sometido el país está ligada a la "sobrecarga de expectativas" de las clases populares respecto a su bienestar ${ }^{4}$. Al contrario, como vimos, O’Donnell parecía mostrar que el problema más bien radicaba en una dinámica conflictiva en la que ninguna de las partes tenía suficiente poder para imponer una hegemonía durable. Ni las clases populares y sus aliados burgueses nacionales, ni la burguesía pampeana y la gran burguesía que jugaba con ella en períodos regresivos. Un diagnóstico que carga las tintas de manera unilateral en las "trabas" para la inversión privada que suponen las regulaciones vinculadas con el mundo del trabajo asalariado, así como en las prestaciones sociales para los informales y los inactivos como freno a una mayor austeridad del Estado, parece sugerir caminos conocidos que llevarían al país a repetir sus ciclos pendulares.

En cuanto a las cuestiones de cultura política, el giro a la derecha construyó, en términos discursivos, una nueva frontera radical con el pasado inmediato, al que asoció, como había sucedido en otros momentos de la historia reciente, con lo "imposible", lo que debía dejarse atrás, in toto, definitivamente. Esta estrategia de legitimación/deslegitimación, que es a la vez un intento de construir una nueva identidad política modernizadora, continúa un rasgo que había caracterizado a la democracia argentina hasta el momento (Aboy Carlés, 2001) y que impedía construir linajes y continuidades en el ciclo democrático. En este caso, el desprecio hacia el "populismo" gobernante entre 2003 y 2015 llevó incluso a la actual coalición gobernante a menospreciar el peso de algunos valores políticos compartidos, como el de las políticas de derechos humanos, que fueron tratadas como elementos de la lucha facciosa. Aunque el actor que encabeza el nuevo período regresivo acepta el juego democrático, este desprecio hacia algunos bienes comunes de la nueva cultura democrática expresa una tensión sociopolítica no resuelta en el país.

En líneas generales, la gran novedad radica en que la alianza aperturista tiene un vehículo electoral de expresión, lo que parece cambiar las condiciones de producción de las mediaciones partidarias en Argentina. Pongamos por caso, la burguesía pampeana desde 1916 no tenía una "fuerza propia" y mucho menos una base electoral sólida. Su dificultad para encontrar una expresión política, así como para construir apoyos sociales y políticos más amplios que los

4 Lo que apareció públicamente en declaraciones como la que realizó el economista de Cambiemos Javier González Fraga: "Le hicieron creer al empleado medio que podía comprarse plasmas y viajar al exterior" (La Nación, 2016). 
de su sector, fue manifiesta (Hora, 2012). A partir de los años noventa del siglo pasado, el agro produjo una modernización productiva (Gras y Hernández, 2016) que le permitió retomar su lugar de "vanguardia dinámica y altamente productiva" de la economía argentina (O’Donnell, 1977, p. 536). Una alianza sostenida en el agronegocio, como la que O'Donnell imaginaba, parece posible en la Argentina actual. Tiene, al menos hasta el presente, una mediación partidaria que la representa y lleva su programa al gobierno.

Como muestran Mangonnet, Murillo y Rubio (2018), la coalición Cambiemos fue la gran depositaria del voto opositor en la zona núcleo de producción agraria - el sector geográfico más rico- en las presidenciales de 2015 (ver Mapa 1). Su claro antagonismo con el kirchnerismo la diferenciaba de otras opciones opositoras. Además, en buena parte, su capacidad de atraer el voto agrario se explica porque el PRO decidió tomar sin cambios el programa en la materia construido por algunas de las entidades más dinámicas del sector, como la Asociación Argentina de Consorcios Regionales de Experimentación Agrícola (AACREA) y por el Foro Agroindustrial en ese tiempo (Mangonnet, Murillo y Rubio, 2018, p. 9). Dicho programa implicaba beneficios directos para el sector, sobre todo ligados a la baja programada de las retenciones a la exportación de soja y la eliminación de las retenciones a otros cereales, como el trigo y el maíz. Tales medidas fueron tomadas por el gobierno de Mauricio Macri no bien asumió.

Mapa 1. Voto a Cambiemos en el balotaje y zonas de mayor productividad agraria. Año 2015.
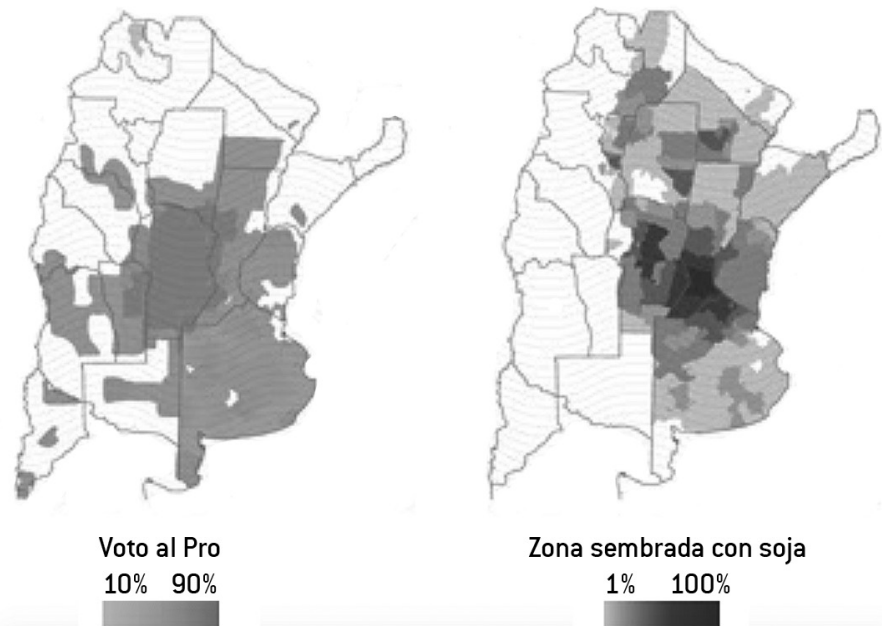

Fuente: Natanson, 2017. 
Junto con ello, el nuevo gobierno produjo una cierta devolución al sector del control del área de gobierno encargada de los asuntos agrícolas. La composición del gabinete del Ministerio de Agroindustria da cuenta de la influencia directa en las políticas en la materia de la Sociedad Rural Argentina (SRA), de AACREA y, en menor medida, de la Confederación de Asociaciones Rurales de Buenos Aires y La Pampa (CARBAP), las entidades más vinculadas con los grandes productores, con las familias más tradicionales del mundo agrario y con los sectores asociados a la producción sojera (Gras y Hernández, 2016) (ver Tabla 1). Este gabinete se contrapone al perfil técnico, apoyado en la burocracia estatal, dado a esa dependencia por el gobierno de Cristina Fernández de Kirchner desde su creación, en 2009 (Mangonnet, Murillo y Rubio, 2018, p. 18).

Tabla 1. Altos funcionarios del Ministerio de Agroindustria [áreas vinculadas con el sector]. Año 2018.

\begin{tabular}{|c|c|c|}
\hline Nombre & Cargo & Rol en el sector corporativo \\
\hline $\begin{array}{l}\text { Luis Miguel } \\
\text { Etchevehere }\end{array}$ & Ministro (desde 2017) & Presidente de la SRA [2012-2017) \\
\hline $\begin{array}{l}\text { Santiago del } \\
\text { Solar Dorrego }\end{array}$ & Jefe de Gabinete (desde 2017) & $\begin{array}{l}\text { Miembro de Comisión Directiva de } \\
\text { AACREA (2011- 2017) y director de } \\
\text { la SRA [2017] }\end{array}$ \\
\hline $\begin{array}{l}\text { Guillermo } \\
\text { Bernaudo }\end{array}$ & $\begin{array}{l}\text { Secretario de Agricultura, } \\
\text { Ganadería y Pesca (desde } \\
\text { 2017), antes jefe de Gabinete }\end{array}$ & $\begin{array}{l}\text { Asesor de CREA (desde 1986), } \\
\text { luego asesor e investigador de } \\
\text { AACREA (desde 2004) }\end{array}$ \\
\hline $\begin{array}{l}\text { William Andrew } \\
\text { Murchison }\end{array}$ & $\begin{array}{l}\text { Secretario de Alimentos y } \\
\text { Bioeconomía (desde 2017) }\end{array}$ & $\begin{array}{l}\text { Delegado de la SRA y miembro del } \\
\text { CREA Villa Valeria }\end{array}$ \\
\hline $\begin{array}{l}\text { Santiago } \\
\text { Hardie }\end{array}$ & $\begin{array}{l}\text { Secretario de Coordinación y } \\
\text { Desarrollo Territorial (desde } \\
\text { 2015) }\end{array}$ & $\begin{array}{l}\text { Exfuncionario de gobierno del PRO } \\
\text { en CABA y gerente general de la } \\
\text { Fundación Pensar (think tank del } \\
\text { PRO) }\end{array}$ \\
\hline Marisa Bircher & $\begin{array}{l}\text { Secretaria de Mercados } \\
\text { Agroindustriales (desde 2015) }\end{array}$ & $\begin{array}{l}\text { Exfuncionaria de gobierno del PRO } \\
\text { en CABA }\end{array}$ \\
\hline $\begin{array}{l}\text { Luis María } \\
\text { Urriza }\end{array}$ & $\begin{array}{l}\text { Subsecretario de Agricultura } \\
\text { (desde 2015) }\end{array}$ & $\begin{array}{l}\text { Miembro del CREA Gualeguaychú, } \\
\text { directivo de AACREA (2013-2015) }\end{array}$ \\
\hline $\begin{array}{l}\text { Rodrigo } \\
\text { Troncoso }\end{array}$ & $\begin{array}{l}\text { Subsecretario de Ganadería } \\
\text { (desde 2015) }\end{array}$ & $\begin{array}{l}\text { Gerente General de la Cámara } \\
\text { Argentina de Engordadores } \\
\text { de Hacienda Vacuna (Cámara } \\
\text { Argentina de Feedlot) (desde 2000) }\end{array}$ \\
\hline
\end{tabular}




\begin{tabular}{lll}
\hline Nombre & Cargo & Rol en el sector corporativo \\
\hline \multirow{2}{*}{ Felipe Crespo } & $\begin{array}{l}\text { Subsecretario de Desarrollo } \\
\text { Territorial (desde 2015) }\end{array}$ & Miembro de la Fundación Pensar \\
\hline \multirow{2}{*}{ Hugo Rossi } & $\begin{array}{l}\text { Subsecretario de Coordinación } \\
\text { Política (desde 2015) }\end{array}$ & $\begin{array}{l}\text { Asesor del área de Agroindustria de } \\
\text { la Fundación Pensar y de CARBAP }\end{array}$ \\
\hline \multirow{2}{*}{$\begin{array}{l}\text { Jesús María } \\
\text { Silveyra }\end{array}$} & Subsecretario de Mercados & $\begin{array}{l}\text { Corredor/operador agropecuario, } \\
\text { miembro fundador de la Asociación } \\
\text { de Productores de Granos de la } \\
\text { República Argentina (APROGRAN) y } \\
\text { de la Fundación para el Progreso en } \\
\text { Libertad (FUPEL) }\end{array}$ \\
\hline
\end{tabular}

Fuente: Sitio web del Ministerio de Agroindustria, 2018.

Las elecciones legislativas de 2017, en las que Cambiemos consolidó su poder electoral y extendió su dominio territorial, confirman la correlación entre el voto a la alianza gobernante y la llamada "zona núcleo" de la producción sojera. La alianza es aún más sólida en los lugares más importantes de actividad agraria, como lo muestra el Mapa 2, en el que se ve la primacía del voto a Cambiemos en el corazón productivo del agro argentino en las legislativas de 2017. La solidez de la alianza se mantuvo inclusive a mediados de 2018, en un contexto de crisis económica: cuando los socios del PRO en Cambiemos propusieron una suspensión de la reducción de las retenciones a las exportaciones de soja, el presidente Macri primero lo desestimó ${ }^{5}$ y luego estableció un régimen sensiblemente más benévolo hacia el sector, basado en una suma fija que se licuaría con el aumento del tipo de cambio ${ }^{6}$, al mismo tiempo que ratificó su cercanía con las asociaciones de productores agropecuarios ${ }^{7}$.

5 Cf., por ejemplo, Infobae, 2018.

6 Cf. El Cronista, 2018.

7 Cf. La Nación, 2018. 
Mapa 2. Voto en zonas agropecuarias en elecciones legislativas de 2017.

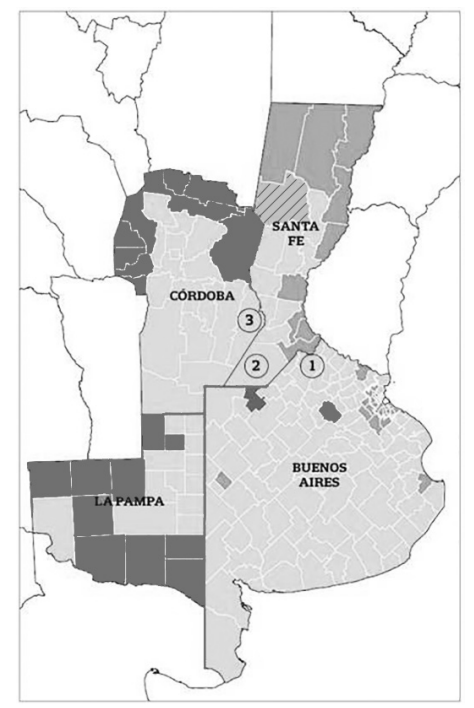

Fuente: La Nación, 2017. *Referencias: gris claro: voto Cambiemos; gris medio: voto FPV (kirchnerismo); gris: voto Frente Renovador; gris rayado: Frente Progresista Cívico y Social; gris oscuro: 1 País.

Si bien no puede establecerse aún la consolidación de un vínculo representativo entre el sector agrario y Cambiemos, hay elementos para pensar que el proceso avanzará en ese sentido. Sin embargo, es menos claro el modo en que esa alianza podría producir un proyecto de dominación durable. El rechazo al peronismo en su versión nacional-popular aceleró la búsqueda de un canal de expresión electoral de vastos sectores económicos asociados a la actividad agropecuaria, así como sucedió con otros sectores del mundo de los negocios (Vommaro, 2017), pero no dio paso hasta el momento a la consolidación de comportamientos económicos consistentes de apoyo al nuevo proceso. Al contrario, en términos de comportamiento de los actores y de economía política de sus relaciones, se advierten más continuidades que rupturas con el diagnóstico brindado por O'Donnell en Estado y alianzas...: ante la derrota de la alianza defensiva, esta vez por vías electorales, se inició una tendencia regresiva en términos de distribución del ingreso - acelerada a partir de 2018 - , que obstaculizó la ampliación del marco de apoyos de la coalición de gobierno.

Más aún, entre sus propios apoyos parece haber fuertes tensiones. Por ejemplo, los intereses de los sectores medios y medio-altos urbanos y los de las fracciones más dinámicas de la burguesía agraria, que fueron los principales sostenes electorales de Cambiemos desde 2015, penden de hilos diferentes, lo que se evidencia, entre otras cuestiones, en el impacto opuesto que tiene en sus ingresos el precio del dólar, cuyo aumento perjudica a los 
consumidores de productos importados y favorece a los exportadores. Con una creciente disminución de los recursos disponibles, la economía política del gobierno de Cambiemos no logró así estabilizar apoyos mayoritarios.

\section{A modo de conclusión}

Volver sobre Estado y alianzas..., a cuarenta años de su publicación, es una forma de revisitar un estilo de estudio de lo político que combinaba preocupación por factores estructurales y procesos políticos, por tendencias de largo plazo y acontecimientos contingentes, y que articulaba las miradas sociológica, politológica y de economía política, lo que se volvió, con los años de hiperespecialización, cada vez menos frecuente en las ciencias sociales latinoamericanas. Este estilo no solo combinaba perspectivas de análisis, sino también trabajo empírico y preguntas teóricas complejas.

Con esa mirada y a partir del esquema analítico construido por O'Donnell para pensar el ciclo pendular iniciado con la caída del primer peronismo, nos ocupamos del proceso político reciente en Argentina. Identificamos allí una novedad en relación con lo que el autor llama la "burguesía pampeana": el haber encontrado una expresión político-electoral competitiva. A ello se suma el hecho de que el sector agrario, convertido ya en los años noventa en un área dinámica de la economía, fue el principal vector del ciclo de crecimiento que tuvo lugar en el país a partir de 2002.

Quizá la novedad política profundice las condiciones del cambio que O’Donnell había identificado en los años de posdictadura y permita dar bases más sólidas a la consolidación de una democracia electoral. Más incierta parece, en cambio, como dijimos, la posibilidad de establecer un modelo socioeconómico hegemónico - en el sentido de que sea capaz de producir consensos en amplios sectores sociales - en el que tanto la burguesía conectada con los mercados mundiales como los actores dependientes del mercado interno se sientan incluidos y, por qué no, protegidos.

La debilidad de la "alianza defensiva" luego de la derrota de 2015 auguró buenas condiciones electorales para el desarrollo de un ciclo aperturista, pero no aseguró ni su éxito de largo plazo ni su capacidad para proyectarse hacia toda la sociedad hasta envolverla casi por completo. Si esto sucediera, por usar la misma fórmula que utiliza O'Donnell al final de su ensayo, "la historia no se habría detenido, pero los conflictos que la tejen ya no serían los que hemos analizado hasta aquî́' (1977, p. 554). 


\section{Referencias bibliográficas}

Aboy Carlés, G. (2001). Las dos fronteras de la democracia argentina: la reformulación de las identidades políticas de Alfonsín a Menem. Rosario: Homo Sapiens.

Acuña, C. (2013). Cuánto importan las instituciones. Gobierno, Estado y actores en la política argentina. Buenos Aires: Siglo XXI.

Aronskind, R. y G. Vommaro (2010). Campos de batalla. Las rutas, los medios y las plazas en el nuevo conflicto agrario. Buenos Aires: UNGS-Prometeo.

Bourdieu, P. (1984). Espace social et genèse des "classes". Actes de la Recherche en Sciences Sociales. 52-53, pp. 3-14.

Canitrot, A. (1980). La disciplina como objetivo de la política económica. Un ensayo sobre el programa económico del gobierno argentino desde 1976. Desarrollo Económico, 19(76), pp. 453-475.

Castellani, A. (2007). Difusión de ámbitos privilegiados de acumulación en la historia argentina reciente. Intervención económica estatal y comportamiento empresario, 1966-1989. Sociohistórica, 21-22, pp. 17-53.

El Cronista (2018). Etchevehere reconoció que "las retenciones en pesos se van a ir diluyendo". El Cronista, [en línea] 8 de septiembre. Disponible en: <https://www. cronista.com/economiapolitica/Etchevehere-reconocio-que-las-retenciones-son-enpesos-y-se-van-a-ir-diluyendo-20180908-0004.html> [acceso 14/9/2018].

Etchemendy, S. (2001). Construir coaliciones reformistas: la política de las compensaciones en el camino argentino hacia la liberalización económica. Desarrollo Económico, 40(160), pp. 675-706.

Germani, G. (1955). Estructura social de la Argentina. Buenos Aires: Raigal.

Germani, G. (1962). Política y sociedad en una época de transición. Buenos Aires: Paidós.

Gras, C. y V. Hernández (2016). Radiografía del nuevo campo argentino. Del terrateniente al empresario transnacional. Buenos Aires: Siglo XXI.

Hora, R. (2012). La evolución del sector agroexportador argentino en el largo plazo, 1880-2010. Historia Agraria, 58, pp. 145-181.

Infobae (2018). Mauricio Macri ratificó ante la Mesa de Enlace el cronograma de reducción de retenciones a la soja. Infobae, [en línea] 3 de julio. Disponible en: <https:// www.infobae.com/politica/2018/07/03/mauricio-macri-ratifico-ante-la-mesa-deenlace-el-cronograma-de-reduccion-de-retenciones-a-la-soja/> [acceso 24/7/2018].

La Nación (2016). González Fraga: "Le hicieron creer al empleado medio que podía comprarse plasmas y viajar al exterior". La Nación, [en línea] 27 de mayo. Disponible en: $<$ https://www.lanacion.com.ar/1903034-gonzalez-fraga-le-hicieron-creer-al-empleado-medio-que-podia-comprarse-plasmas-y-viajar-al-exterior> [acceso 24/7/2018].

La Nación (2017). El voto rural fue para Cambiemos. La Nación, [en línea] 15 de agosto. Disponible en: <https://www.lanacion.com.ar/2053223-el-voto-rural-fue-para-cambiemos> [acceso 24/7/2018].

La Nación (2018). Macri dijo que la suba de retenciones es "el último esfuerzo temporal" y que "no hay otro camino". La Nación, [en línea] 13 de septiembre. Disponible en: $<$ https://www.lanacion.com.ar/2171574-en-acto-campo-macri-pidio-ultimo-esfuerzo> [acceso 14/9/2018]. 
Mangonnet, J.; M. V. Murillo y J. M. Rubio (2018). Local Economic Voting and the Agricultural Boom in Argentina, 2007-2015. Latin America Politics and Society, 60(3), pp. 27-53.

Mann, M. (1984). The autonomous power of the state: its origins, mechanisms and results. European Journal of Sociology, 25(2), pp. 185-213.

Merklen, D. (2005). Pobres ciudadanos. Las clases populares en la era democrática (Argentina, 1983-2003). Buenos Aires: Gorla.

Ministerio de Agroindustria < https://www.agroindustria.gob.ar/sitio/areas/ministerio/estructura/ $>$ [acceso 24/07/2018].

Murillo, M. V. (1997). La adaptación del sindicalismo argentino a las reformas de mercado en la primera presidencia de Menem. Desarrollo Económico, 37(147), pp. 419-446.

Natanson, J. (2017). El ascenso del PRO. El Atlas de la Argentina. Buenos Aires: Capital Intelectual, pp. 18-19.

O’Donnell, G. (1977). Estado y alianzas en la Argentina, 1956-1976. Desarrollo Económico, 16(64), pp. 523-554.

O’Donnell, G. (1982). El estado burocrático autoritario. Buenos Aires: Editorial de Belgrano.

O’Donnell, G. (1984). ¿Y a mí, que me importa? Notas sobre sociabilidad y política en Argentina y Brasil. Working Paper 9. Notre Dame: Universidad de Notre Dame, Helen Kellogg Institute for International Studies.

Portantiero, J. C. (1977). Economía y política en la crisis argentina. 1958-73. Revista Mexicana de Sociología, 39(2), pp. 531-565.

Sidicaro, R. (2002). Los tres peronismos. Estado y poder económico. Buenos Aires: Siglo XXI.

Torre, J. C. (2003). Los huérfanos de la política de partidos Sobre los alcances y la naturaleza de la crisis de representación partidaria. Desarrollo Económico, 42(168), pp. 647-665.

Vommaro, G. (2017). La larga marcha de Cambiemos. Buenos Aires: Siglo XXI.

Vommaro, G. y M. Gené (2017a). Argentina: el año de Cambiemos. Revista Ciencia Política, 37(2), pp. 231-253.

Vommaro, G. y M. Gené (2017b). Introducción. La sociología política y sus aportes para analizar la política argentina reciente. En: G. Vommaro y M. Gené (comps.). La vida social del mundo político. Investigaciones recientes en sociología política. Buenos Aires: UNGS, pp. 9-34.

Vommaro, G.; S. Morresi y A. Bellotti (2015). Mundo PRO. Buenos Aires: Planeta. 